\title{
Effect of Teucrium Polium Leaf Extracts on AMPK Level in Isolated Rat Pancreases
}

\author{
Durdi Quje ${ }^{1,2^{*}}$, Mohsen Tatar ${ }^{2}$, Farideh Feizi ${ }^{3}$, Hadi Parsian ${ }^{1,2}$, Sohrab Halalkhor ${ }^{2}$ \\ ${ }^{1}$ Cellular and Molecular Biology Research Center (CMBRC), Babol University of Medical Sciences, Babol, Iran. \\ ${ }^{2}$ Department of Biochemistry and Biophysics, Faculty of Medicine, Babol University of Medical Sciences, Babol, Iran. \\ ${ }^{3}$ Department of Anatomical Sciences, Faculty of Medicine, Babol University of Medical Sciences, Babol, Iran.
}

\section{Received: 17 Oct 2013}

Revised : 20 Nov 2013

Accepted: 15 Dec 2013

Corresponding Authors:

Durdi Qujeq

Cellular and Molecular Biology

Research Center (CMBRC), Babol

University of Medical Sciences,

Ganjafrooze Avenue, Babol, Iran.

Phone: +98-112199596

E-mail: d.qujeq@mubabol.ac.ir

\begin{abstract}
Background: The purpose of this study is to evaluate effects of Teucrium polium (TP) leaf extracts on adenosine monophosphate activated protein kinase (AMPK) level in isolated pancreases.

Materials and Methods: In this experimental study, two groups of rats were used as a control group, and diabetic group. In the end of experimental period the animals were sacrificed then pancreas was removed, then isolated rat pancreas was cultured in buffer with or without TP leaf extracts. Measuring the sample glucose level was carried out by spectrophotometric method (Jenway, Model 6505, UK, Pars Azmmon Co., Tehran, IRAN). Insulin level was assayed by an enzyme immunoassay ELISA kit specific for rats made by Mercodia Rat insulin ELISA (10-1250-01, Mercodia AB, Uppsala, Sweden). The adenosine monophosphate activated protein kinase level was determined by ELISA assay method using a rat phosphorylated AMPK ELISA kit (CSB-E11337r, Cusabio Biotech Co., LTD).

Results: The results indicate that addition of TP leaf extract significantly increased AMPK level and insulin content compared to untreated group $(\mathrm{p}<0.05)$. Conclusion: These results support the potential of TP leaf extract as a therapeutic modality for diabetes. However, further studies will be necessary to confirm this potential
\end{abstract}

Keywords: Adenosine monophosphate-activated protein kinase; Teucrium polium; Leaf extract; Pancreas; Rat

Please cite this article as: Quje D, Tatar M, Feizi F, Parsian H, Halalkhor S. Effect of Teucrium Polium Leaf Extracts on AMPK Level in Isolated Rat Pancreases. Res Mol Med. 2013; 1 (3): 29-33.

\section{Introduction}

A number of studies demonstrated that Teucrium polium (TP) have long been recognized in folk medicine in the treatment of diabetes (1). In addition, there are some reports in the literature showing that one of the traditional hypoglycemic herbs is TP (2). In this regard, several researches have shown that this plant has hypoglycemic activities (3-5). However, the molecular mechanism leading to the hypoglycemic effects of TP are still unknown (5). Earlier studies have indicated that the administration of TP boiling extract had an anti-diabetic effect on diabetic rats (6). Previous studies representsthat AMP-activated protein kinas plays an important role in the regulation of œllular energy homeostasis (7-9). Several experimental studies have suggested that AMPK master metabolic regulator of the eukaryotic cell (10). As reported by many investigators AMPK is an enzyme that activated by stress signals $(11,12)$, and also by an elevation in the AMP/ATP and NAD: NADH ratio $(13,14)$. Evidence from many studies showed that in low energy status, AMPK act by stimulating energy producing pathways. These seem to be mainly due to the marked increase in glucose uptake, and an inhibition of glycogen (15). It is now clear that AMPK has been shown to be an important mediator of glucose uptake (16). On the other side, a vast majority of the studies show that AMPK stimulates glucose uptake $(17,18)$. Many studies showed that inhibition of AMPK plays a role in the acute stimulation of insulin secretion by glucose (19). According to the recent work it is widely known that AMPK is an enzyme that is potential benefits in 
glucose homoeostasis, and the energy charge. Previous studies of AMPK activation have concluded that this enzyme acts as a sensor to modulate appropriately cellular metabolism $(20,21)$. The objective of this practical work was to study the possible effects of TP leaf extract on AMPK level and insulin content in isolated pancreases.

\section{Materials and Methods}

Teucrium polium leaf

TP leaves were collected from the suburbs of Babol city, Iran and the plant was identified by the center for Agricultural Research and Natural Resources of Mazandaran Province, Iran. The leaves were separated and dried at room temperature while keeping away from direct sunlight and then was grounded into powder as previously described (22).

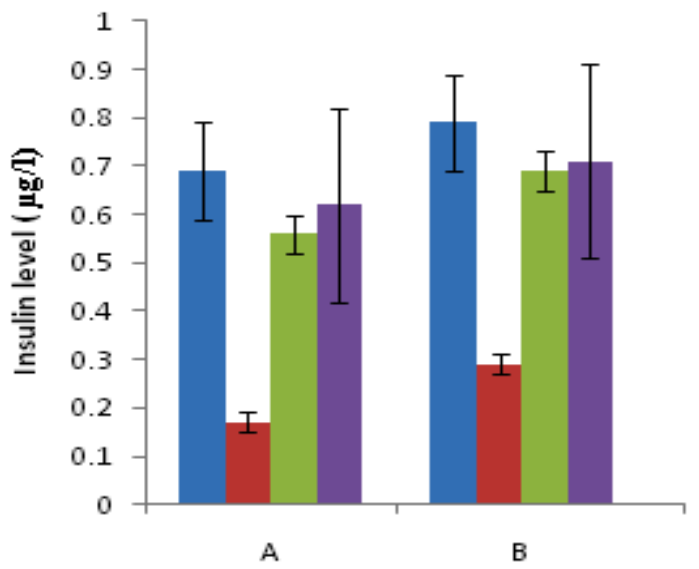

Figure 1. Insulin level $(\mu \mathrm{g} / \mathrm{L})$ at incubated pancreatic tissue with dose $500 \mu \mathrm{g} / \mathrm{L}$ Teucrium polium leaf extracts in the presence of 2.8 $\mathrm{mmol} / \mathrm{L}$ glucose. Part A: control, without TP leaf extract; Part B incubation with TP leaf extract. In each part Column 1, control; Column 2, diabetic; column 3, with aqueous extract; column 4, with ethanolic extract).

\section{The aqueous and alcoholic extract of TP Leaf}

In order to prepare the aqueous concentrate, $100 \mathrm{~g}$ of dry TP leaves dried at room temperature and were infused in two litres of ionized water and were boiled (Behdad-water bath, $80{ }^{\circ} \mathrm{C}$ ) for 30 minutes with an occasional stirring as described before (22). Then the resulted powder was filtered and, non soluble parts were separated by a mesh. Prepared solution passed two times through Whatman paper No. 2, and aqueous was evaporated on a rotator evaporator ( $\mathrm{K}$ 1 Karwerke, GMBH S Co .KG, Germany, TYP: RVo6ML, 010388949) at $75{ }^{\circ} \mathrm{C}$ to reduce the solution volume to one-fifth of initial value. For the preparation of alcoholic solution, $100 \mathrm{~g}$ of dry powder was dissolved in one litre of $96 \%$ ethanol and mixed by a shaker (Labtron -Ls-100) for 24 hours in room temperature. Again the non soluble parts were separated using mesh and the solution was passed two times through Whatman paper No. 2. The macerate was filtered, and ethanol was evaporated on a rotator evaporator at $60{ }^{\circ} \mathrm{C}$ under the vacuum to reduce the solution volume to one-fifth of initial value. Both aqueous and ethanol solutions were kept four days under hood to let the solvents evaporate. Finally, the extract was stored at $-20^{\circ} \mathrm{C}$ until its use.

\section{Isolation of TP leaf fractions}

One part of TP aerial parts extracts was transferred in a column. Ethanol/water $[30-70 \% \quad(\mathrm{v} / \mathrm{v})]$ elution mediums were used as described previously (22). Each fraction was then characterized. Fifth fraction was used in all experiments.

\section{Animals}

Rats weighting between 210-240 g were selected. Rats were prepared from the animal center of Babol University, Babol, Iran. The rats were divided into two groups; control group and diabetic group. All protocols involving animals were approved by Babol University Animal Care and Use Committee. All experimental manipulations were carried out with the animal under ether inhalation anesthesia. The approval of the Ethics Committee of Babol University was also obtained (\# 3546, and 1815).

\section{Diabetic Status}

Diabetes status was induced by a single i.p. injection of STZ (50 mg/kg body weight) to overnight fasted rats. In addition, normal saline was injected to rats in the control groups. Rats with fasting glycemia more than $250 \mathrm{mg} / \mathrm{dl}$ were used as diabetic.

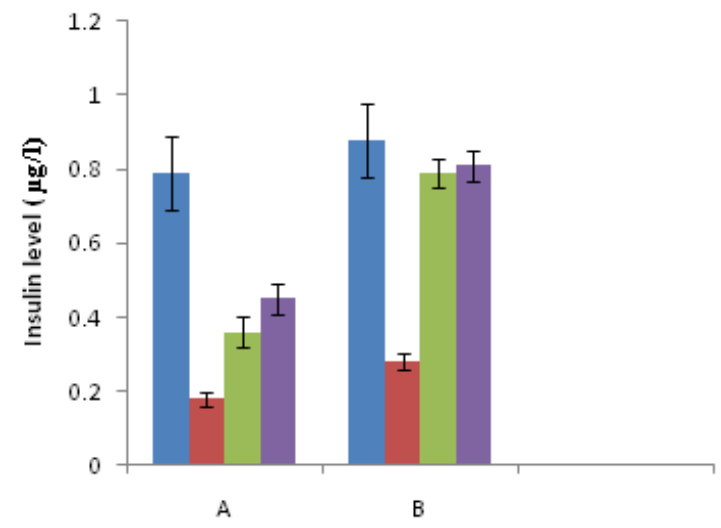

Figure 2. Insulin level $(\mu \mathrm{g} / \mathrm{l})$ at incubated pancreatic tissue with dose $500 \mu \mathrm{g} / \mathrm{L}$ Teucrium polium leaf extracts in the presence of $16.7 \mathrm{mmol} /$ Lglucose. Part A: control, without TP leaf extract; Part B: incubation with TP leaf extract. In each part Column 1, control; Column 2, diabetic; column 3, with aqueous extract; column 4, with ethanolic extract).

\section{Preparation of pancreatic homogenat}

In the end of each experimental period, rats in two groups were killed and their pancreases were 
removed, and digested tissue was washed in Hank's balanced salt solution (HHBS). Sample preparation was carried out as quickly as possible.

\section{TP leaf extract treatment}

Digested tissue was incubated in $1 \mathrm{ml}$ of the RPMI 1640 then TP extract was added to the plates supernatant of each plate was taken, insulin and AMP-activated protein kinase (AMPK) levels were assayed by ELISA method.

\section{Glucose, insulin and AMPK level measurement}

Measuring the sample glucose level was carried out by spectrophotometric method (Jenway, Model 6505, UK, Pars Azmmon Co., Tehran, IRAN). Insulin level was assayed by an enzyme immunoassay ELISA kit specific for rats made by Mercodia Rat insulin ELISA (10-1250-01, Mercodia AB, Uppsala, Sweden). The adenosine monophosphate activated protein kinase level was determined by ELISA assay method using a rat phosphorylated adenosine monophosphate activated protein kinase (AMPK) ELISA kit (CSBE11337r, Cusabio Biotech Co .,LTD).

\section{Statistical analysis}

All data have are expressed as mean \pm SD. Statistical analysis was done using SPSS version 18.0.The significance of differences between the mean values was determined by an unpaired two-tailed Student's t-test. A $p$ value less than 0.05 was considered statistically significant.

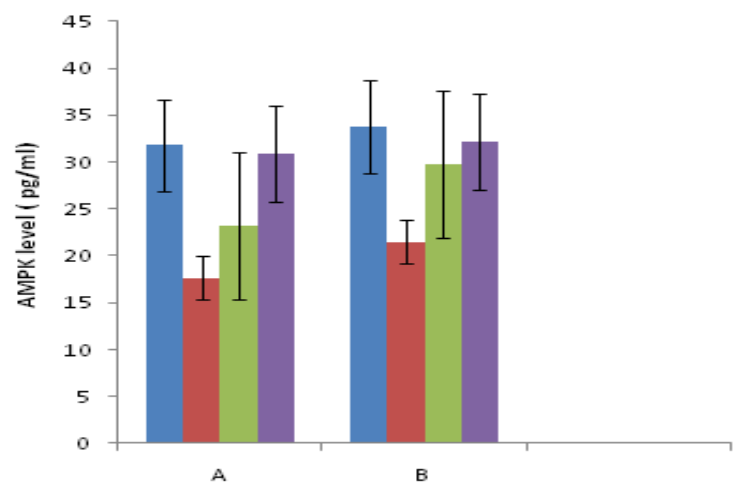

Figure 3. AMPK level ( $\mathrm{pg} / \mathrm{mL})$ at incubated pancreatic tissue with dose $500 \mu \mathrm{g} / \mathrm{L}$ Teucrium polium leaf extracts in the presence of $2.8 \mathrm{mmol} / \mathrm{L}$ glucose. Part A: control, without TP leaf extract; Part B: incubation with TP leaf extract. In each part, Column 1: control, Column 2: diabetic, column 3: with aqueous extract, column 4: with ethanolic extract).

Results

It is interesting that we observed that $500 \mu \mathrm{g} / \mathrm{L}$ of the TP leaf extract powder/mL caused a significant $(P<0.05)$ increase in insulin release during incubation .also, $500 \mu \mathrm{g}$ of the TP leaf extract powder/mL caused a significant $(P<0.05)$ increase in AMPK level during incubation.

We incubated pancreatic tissue with $500 \mu \mathrm{g} / \mathrm{L}$ TP leaf extract in the presence of 2.8 and /or $16.7 \mathrm{mmol} / \mathrm{L}$ glucose. Addition of TP leaf extract increased insulin secretion by $0.71 \pm 0.1$ vs $0.17 \pm 0.05(\mathrm{p}<0.05)$ at 2.8 $\mathrm{mmol} / \mathrm{L}$ glucose concentration and $0.81 \pm 0.11$ vs. $0.18 \pm 0.08 \quad(\mathrm{p}<0.05)$ at $16.7 \mathrm{mmol} / \mathrm{L}$ glucose concentration, respectively (Fig 1, 2). When rat pancreatic were challenged with $2.8 \mathrm{mmol} / \mathrm{L}$ glucose in the presence of TP leaf extract, AMPK was stimulated $32.17 \pm 3.53$ vs. $17.65 \pm 3.21(\mathrm{p}<0.05)$, and $30.14 \pm 3.14$ vs. $17.83 \pm 2.16(\mathrm{p}<0.05)$ at 16.7 $\mathrm{mmol} / \mathrm{L}$ glucose concentration, respectively.

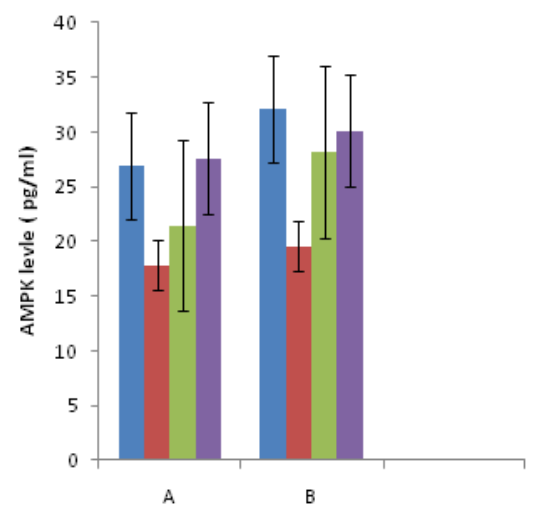

Figure 4. AMPK level $(\mathrm{pg} / \mathrm{ml})$ at incubated pancreatic tissue with dose $500 \mu \mathrm{g} / \mathrm{LTeucrium}$ polium leaf extracts in the presence of $16.7 \mathrm{mmol} / \mathrm{L}$ glucose. Part A: control, without TP leaf extract; Part B: incubation with TP leaf extract. In each part Column 1, control; Column 2, diabetic; column 3, with aqueous extract; column 4 , with ethanolic extract).

As it is evident from our findings TP leaf extract can cause a little increasing in insulin secretion. The results of present studies indicate that TP leaf extract was found to increase AMPK level in normal and in the animals made hyperglycemic with STZ. The effects of TP aerial parts extracts in STZ induced diabetic rats are shown in the (Fig 3,4).

\section{Discussion}

Our study provided the direct evidence that T. polium leaf extracts regulated AMPK level in pancreatic tissue. It should be noted that AMPK is a signal of glucose content, which regulates fuel process (7). Furthermore, AMPK interaction has been considered as an important site of intervention metabolites in diabetes $(8,15)$. Since alterations in AMPK level can Modulate energy balance (11); it is possible that this effect has also an important role in glucose metabolism. In pancreas incubated with $\mathrm{TP}$ leaf extracts, we observed also an increase in insulin content. This observation is in agreement with the 
results obtained by other investigators $(3,4)$. In pancreas incubated with TP leaf extracts AMPK activity is increased by elevations in glucose concentration indicating that AMPK could play a role in insulin release acting as a fuel sensor. This observation is in agreement with the results obtained by other investigations (15, 18-19). These results suggest that stimulation of AMPK level could play a role in insulin release. The biochemical relevance of these findings is unclear. As previously mentioned, AMPK has been involved in control of glucose metabolism. The exact mechanism of the pancreatic changes due to TP leaf extracts in vitro models is not clear but there are some possible mechanisms of these alterations in the pancreatic cells. Our results indicated that increased insulin level by TP leaf extracts might be due to regeneration in the $\beta$ cells. These changes also may be influenced by components in the extract of TP leaf extracts. However, there are other extra pancreatic mechanisms such as enhanced glucose transport into the cells, inhibition of the endogenous glucose production and change the glucose metabolism.

In conclusion

\section{Conclusion}

In the present study, higher levels of AMPK were seen in $T$. polium leaf extracts treated samples as compared with control samples. These results suggest that AMPK can be targeted for the treatment of diabetic. Our results showed that it may be possible to develop therapies for diabetes by increasing AMPK levels with plant materials extracts. It is possible that this result may elucidate the mechanism by which TP inhibits glucose accumulation. This is an important issue for future research.

\section{Acknowledgements}

We are grateful to the Departments of Biochemistry and Anatomical Sciences, at Babol University School of Medicine for their assistance in blood collection and pancreas tissue samples. This investigation was a collaborative work of the Cellular and Molecular Biology Research Center and the Faculty of Medicine. The financial aid has been provided by the Research Council of University. We acknowledge support from the Research Council of Babol University of Medical Sciences.

\section{References}

1. Afifia FU, Al-Khalidib B, Khalil E. Studies on the in vivo hypoglycemic activities of two medicinal plants used in the treatment of diabetes in Jordanian traditional medicine following intranasal administration. J Ethnopharmacol. 2005; 100(3): 314-8. PMID: 15885943

2. Baluchnejadmojarad T, Roghani M, Roghani- Dehkordi F.
Antinociceptive effect of Teucrium polium leaf extract in the diabetic rat formalin test. J Ethnopharmacol. 2005; 97: 207-210. PMID: 15707753

3. Gharaibeh MN, Elayan HH, Salhab AS. Hypoglycemic effects of Teucrium polium. J Ethnopharmacol. 1988; 24: 93-9. PMID: 3199839

4. Esmaeili MA, Yazdanparast R. Hypoglycaemic effect of Teucrium polium: studies with rat pancreatic islets. J Ethnopharmacol. 2004; 95: 27-30. PMID:15374603

5. Zal F, Vasi M, Rast M, Vessal, M. Hepatotoxicity associated with hypoglycemic effects of Teucrium polium in diabetic male rats. Arch. Iran. Medicine. 2001; 4: 188-192.

6. Vahidi AR, Dashti-Rahmatabadi MH, Bagheri SM. The Effect of Teucrium Polium Boiled Extract in Diabetic Rats. Iranian Journal Of Diabetes And Obesity. 2010; 2: 27-32.

7. Kahn BB, Alquier T, Carling D, Hardie DG. AMP-activated protein kinase: ancient energy gauge provides clues to modern understanding of metabolism. Cell Metabolism. 2005; 1: 15-25. PMID: 16054041

8. Carling D. The AMP-activated protein kinase cascade: a unifying system for energy control. Trends Biochem. Sci. 2004; 29: 18-24. PMID: 14729328

9. Hardie DG. The AMP-activated protein kinase pathway-new players upstream and downstream. J Cell Sci. 2004; 117: 54795487. PMID: 15509864

10. Hardie DG. Minireview: the AMP-activated protein kinase cascade: the key sensor of cellular energy status. Endocrinology. 2003; 144: 5179-83. PMID: 12960015

11. Shaw RJ, Kosmatka M, Bardeesy $\mathrm{N}$ et al. The tumor suppressor LKB1 kinase directly activates AMP-activated kinase and regulates apoptosis in response to energy stress. Proc Natl Acad Sci USA. 2004; 101: 3329-35. PMID: 14985505

12. Corton JM, Gillespie JG, Hardie DG. Role of the AMP activated protein kinase in the cellular stress response. Curr. Biol. 1994; 4: 315-24. PMID: 7922340

13. Rafaeloff-Phail R, Ding L, Conner L, Yeh WK, Mcclure D, Guo $\mathrm{H}$ et al. Biochemical regulation of mammalian AMP-activated protein kinase activity by NAD and NADH. J Biol Chem. 2004; 279: 52934-39. PMID: 15465812

14. Rutter GA, Da Silva Xavier G, Leclerc I. Roles of 5AMPactivated protein kinase (AMPK) in mammalian glucose homoeostasis. Biochem J. 2003; 375: 1-16. PMID: 12839490

15. Viollet B, Lantier L, Devin-Leclerc J, et al. Targeting the AMPK pathway for the treatment of Type 2 diabetes.Front Biosci. 2009; 1: 3380-400. PMID: 19273282

16. Mu J, Brozinick JT, Valladares JO, et al. A role for AMPactivated protein kinase in contraction- and hypoxia-regulated glucose transport in skeletal muscle, Mol. Cell. 2001; 7: 1085-94. PMID: 11389854

17. Fryer LG, Foufelle F, Barnes K, et al. Characterization of the role of the AMP- activated protein kinase in the stimulation of glucose transport in skeletal muscle cells. Biochem. J. 2002; 363: 167-74. PMID: 11903059 
18. Kurth-Kraczek EJ, Hirshman MF, Goodyear LJ, et al. 5 AMPactivated protein kinase activation causes GLUT4 translocation in skeletal muscle, Diabetes. 1999; 48: 1667-71. PMID: 10426389

19. Tsuboi T, Da Silva Xavier G, Leclerc I, Rutter GA. 5-AMPactivated Protein Kinase Controls Insulin-containing Secretory Vesicle Dynamics. The Journal Of Biological Chemistry. 2003; 278: 52042-51. PMID: 14532293

20. Abbud W, Habinowski S, Zhang JZ, Kendrew J, Elkairi FS, Kemp BE et al. Stimulation of AMP-activated protein kinase (AMPK) is associated with enhancement of Glut1-mediated glucose transport. Arch Biochem Biophys. 2000; 380: 347-52. PMID: 10933890
21. Cidad P, Almeida A, Bolanos JP. Inhibition of mitochondrial respiration by nitric oxide rapidly stimulates cytoprotective GLUT3-mediated glucose uptake through 50-AMP-activated protein kinase. Biochem J. 2004; 384: 629-36. PMID: 15320870

22. Qujeq D, Tatar M, Feizi F, ParsianH, Halalkhor S: Effects of Teucrium polium aerial parts extracts on Malonyl-CoA decarboxylase level. Molecular Biology Research Communications. 2013; 2 (4): 101-107. 